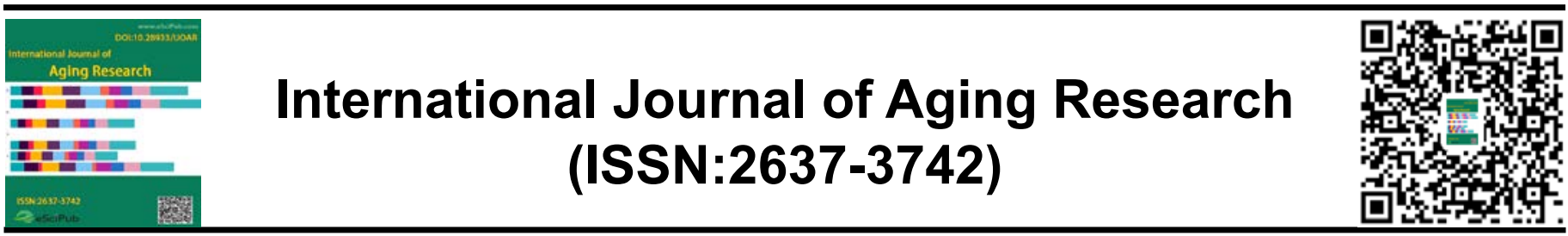

\title{
PSYCHIC DIAGNOSIS OF THE FAMILY CAREGIVER OF THE ALZHEIMER: CASE STUDY OF A BASIC HEALTH UNIT
}

\begin{abstract}
Milena Pereira da Silva ${ }^{*}$, Jhonata Willian Amaral Sousa ${ }^{2}$, Isabella Francilayne de Jesus Lima $^{3}$, Débora Aline de Souza Ribeiro ${ }^{4}$, João Murilo dos Santos ${ }^{5}$.
\end{abstract}

Centro Universitário - UNISÃOMIGUEL ${ }^{12345}$.

\section{ABSTRACT}

Introduction: Alzheimer's disease (AD) is a chronic degenera${ }^{*}$ Correspondence to Author: tive disease that compromises the physical, mental and social integrity of the elderly, and therefore leads to an increasing dependence on care, and almost always linked to family dynamMilena Pereira da Silva ics and performed at home. Objectives: The main objective of this research is to analyze the daily lives of family caregivers of patients with AD. Methodology: The qualitative approach was used. Data were collected in the municipality of Tamandaré/PE, through semi-structured interviews with ten family caregivers of patients with Alzheimer's disease. In addition to the interview, a structured questionnaire with closed-ended questions was applied, referring to the general and personal characteristics of each interviewee. For data analysis, the verbatim reports were fully transcribed, where relevant aspects were observed and organized into two categories: impact of diagnosis and challenges in caring. Results: The results showed that all coexistence and adaptation to this new reality modify the style and quality of life of those involved. The changes are significant and need to be understood and incorporated into the family routine. Negative emotional reactions involving impotence, fear and anger are common, besides a deep feeling of injustice. Conclusion: The study showed the need for assistance that includes all affected family members. The nurse should support and contribute to Centro Universitário - UNISÃOMIGUEL

How to cite this article:

Milena Pereira da Silva, Jhonata Willian Amaral Sousa, Isabella Francilayne de Jesus Lima, Débora Aline de Souza Ribeiro, João Murilo dos Santos. PSYCHIC DIAGNOSIS OF THE FAMILY CAREGIVER OF THE ALZHEIMER: CASE STUDY OF A BASIC HEALTH UNIT. International Journal of Aging Research, $2020,3: 59$

overcoming the difficulties faced from the moment of diagnosis to the most advanced stages of the disease.

Keywords: Emotions, Alzheimer's disease, caregivers. 


\section{INTRODUCTION}

The family institution has emerged since the beginning of humanity; its concept is based on different people, in the physical and psychological characteristics, however, linked by the bond of consanguinity, which start to live together, in such a way that the loss or disability of one member causes the destructuring of others ${ }^{1}$.

Ageing is a process in which every human being is subject to pass, it is the final phase of man's life and begins from the age of 60 in developing countries and 65 in developed countries, according to the World Health Organization. The family is the most important entity to ensure that the elderly can live independently in their homes. And because of the increase in life expectancy, the relationship between parents and children is becoming more lasting. More adult children are caregivers of elderly parents who are disabled or debilitated because of a wide variety of diseases ${ }^{2}$.

Currently in Brazil, the number of elderly is high due to the improvement in quality of life added to the decrease in birth rates and mortality, in addition to advances in the health area. It is estimated that, by 2025, Brazil will become the sixth country in individuals aged 60 years or more, representing approximately $13 \%$ of the population ${ }^{3}$.

The transformations in the epidemiological profile show the predominance of chronic degenerative diseases that can compromise the autonomy of the elderly, requiring the presence of a caregiver to provide continuous care to them ${ }^{4}$.

In this context, Alzheimer's disease (AD) is included as a form of dementia that compromises the physical, mental and social integrity of the elderly, leading to an increasing dependence on care, almost always linked to family dynamics and performed at home ${ }^{5}$.

Receiving the diagnosis of $A D$ has a great impact on the lives of patients and their families. Due to the fact that there is no cure and the progression of symptoms. Emotional reactions involving impotence, apprehension and anger are frequent, besides many doubts ${ }^{6}$.

According to the Brazilian Alzheimer's Association $^{7}$, participating in the process of cognitive degeneration causing disability confronts the caregiver-family with fear about his future and that of his family, because he is forced to reorganize his daily life. Watching his family member gradually lose his identity generates intense suffering and impotence, and the relationship with the patient becomes a confrontation with many losses that need to be continuously adapted.

Alzheimer's disease is a great challenge for all people involved, equally important to the support offered to people with $A D$, is the support offered to caregivers, because they have indispensable action, and any adaptation to this new reality makes the family member experience an exacerbated sense of responsibility in opposition to a reduced sense of freedom, involving losses in personal life such as decreased time for himself, sleep deprivation, dedication only to the family affected by the disease, renunciation of the present and the future ${ }^{7}$

\section{OBJECTIVES}

This research project has as its theme: Psychological Diagnosis of the Family Caregiver of the Alzheimer: Case Study of a Basic Health Unit, of the Adstrita Area of the UBS Leopoldo Lins of the Municipality of Tamandaré - PE. In this sense, this study seeks to understand the physical and psychological confrontations of the family caregiver, and describe the coexistence with an Alzheimer's patient, in addition to highlighting the need for assistance that includes all affected family members.

\section{METHODS}

This is a descriptive research with a quantitative approach. Ten family caregivers of elderly people with Alzheimer's disease, from the Leopoldo Lins UBS area, participated in the research. The research was carried out in the 
UBS (basic health unit) of the Leopoldo Lins area of the municipality of Tamandaré-PE. Data were collected in March 2019. The data were collected through the application of a structured questionnaire with closed-ended questions, referring to the general and personal characteristics of each interviewee, which allows acquiring reference on age, gender, education, occupation, time of work as a caregiver, life habits, among others. And a semi-structured interview on the theme, the difficulties, changes in daily life, feelings experienced.

To conduct this research, a letter of consent was sent to the Secretariat of Health of the municipality of Tamandaré, requesting authorization to conduct the research. In addition, the approval of the ethics committee was requested through the submission of the project to the Brazil Platform to begin data collection.

After the authorization of the Secretary of Health and the research ethics committee of their respective teachers, contact was made with the nurse of UBS Leopoldo Lins, who provided a list of ten elderly people with Alzheimer's and their respective families who met the criteria for inclusion of this study.

Subsequently, contact was made with the families of patients with $A D$ to make the necessary clarifications and, based on their availability to participate in the survey; the day and time of the interviews were scheduled.

First, the families signed the Free and Informed Consent Form; data collection took place at the residence of the family caregiver participating in the research. The interviews took place individually and lasted an average of thirty minutes. Ten interviews were conducted; all recorded with the consent of the interviewees, in order to later transcribe verbatim reports in full.

In addition to the interview, a structured questionnaire with closed-ended questions was applied, referring to the general and personal characteristics of each interviewee, which allowed acquiring reference on age, gender, education, occupation, time of performance as a caregiver, life habits, among others.

The quantitative descriptive approach was used to analyze the data of this research, first the interviews were carefully listened to to identify the systematization of ideas, then the speeches were copied in full and the researchers performed a thorough reading to identify the categories of analysis following the interpretations, the anonymity of the volunteers was preserved and these will be identified by the initial letter of the word Caregiver (C) followed by sequential numbers $(\mathrm{C} 1, \mathrm{C} 2 \ldots)$. The research project was referred to the Research Ethics Committee of Hospital Otávio de Freitas, attended to the legal aspects for conducting research with human beings and obtained approval under protocol number 3.329.268.

\section{RESULTS}

Regarding the general profile of the caregivers, it was found thatnine of the ten interviewed are women (90\%), have ages ranging Between 21 and 54 years, act as caregivers for periods ranging from 4 months to 5 years, and $90 \%$ have experience in the role of at least 1 year, nine of the ten caregivers also reported never having taken a course to act as caregiver. The results converged with the findings in the literature. After listening to the interviews and transcribing the verbal reports, it was possible to highlight two thematic units: "Impact of the diagnosis" and "Challenges in caring".

\section{Diagnostic Impact}

In the thematic unit "Impact of the diagnosis", based on the reports, it was possible to understand the feelings that affect family members at the time of the initial shock of the discovery and they vary from surprise to a certain conformity by the foreboding already observed previously, which suggests a late diagnosis:

As I had been living with him for a long time, I was noticing, his forgetfulness (C1).

For me it was not so shocking, because we already suspected... (C2). 
Demonstrations of insecurity due to the unknown of the new reality to which they were abruptly inserted and tension due to the inversion of the family role.

The timing of the diagnosis was horrible, very bad because mom would not accept me to take care of her (C3).

It was the worst thing that exists on the face of the Earth, because we didn't know how to deal with it... when

it was diagnosed, I already thought about death (C6).

On the other hand, the caregiver attribution given to the family member seems to further strengthen the ties between the family member and the Alzheimer's patient, generating feelings of retribution and perseverance in facing this difficult task, and the role of caregiver is even placed as a divine mission:

I think my love grew a lot more for her when I saw that situation (C6).

I feel as if it were an experience, something that God had put into my life to make me stronger, and I feel very happy to help him and because he is very affectionate too (C5).

God is giving me strength and I keep on fighting, if God wanted it that way, I have to take care of it to the end (C10).

It was a way to love my mother even more, because every time I read the Bible, I sing hymns to her; I demonstrate the love I have for her (C3).

Upon receiving the news of a family member with Alzheimer's and being submitted to the role of caregiver, many transformations occur in the lives of these people, especially the change of residence to stay close to the dependent family member and dedicate themselves totally and this generates loss of autonomy and wear and tear further overloading the exercise of the function.

I live in Recife, so I had to get organized for every weekend to be here (Tamandaré); I give up staying with my husband, the church, friends, everything ... (C4).

I lived in Recife, but the confirmation of the diagnosis, I decided to leave here (Tamandaré), I even left my job (C2).

Regarding the disease, most of them report ignorance, some even try to research it, but others play the role of the caregiver in a totally empirical way:

The first thing I did was look on the internet, when I researched I saw the consequences was not easy no, it is a sadness we only think about the worst, right? That the "time" will come, in the work that will give, in the suffering that she was going to go through (C9).

I've never researched (C6).

I didn't study the disease (C5).

The research I do is only when I talk to the doctor; I remove some doubts with him (C1).

\section{Care Challenges}

In the thematic unit "Challenges in caring", the difficulties reported were varied, reporting the lack of rotation with other family members in the exercise of the function, the mood changes, common in people with Alzheimer's and the small contribution of the health team in care or in the provision of information. The burden of accomplishing such an arduous mission practically alone was highlighted by some caregivers:

Unfortunately not everyone was aware, a lot of people went away and ended up being left to me, I think that if there was more dedication of all who were close, she wouldn't reach this stage so fast (C4).

It's the biggest stress and no one has the willingness to stay with her (C6).

Reference to impotence before the new reality:

Tired, anguished because you see the person you love in that picture and you can't do anything... you want to reverse that, but you can't, there is no cure. I wish no one (C8).

The characteristic mood swings of the Alzheimer's sufferer also cause wear and tear on 
caregivers and make them even more insecure to continue to perform their task.

When people don't have the patience to talk to him, he gets aggressive, if you contradict him; he gets angry (C5).

He has to know how to deal with it, because there is a day when he dawns putting defect in everything, sometimes he doesn't want to eat lunch, doesn't want to take the medicine, he says he's already taken it and won't take it anymore, these are the biggest difficulties. Besides, there is a change of mood, there are days when he dawns calmly, there are days when he dawns agitated, and he doesn't want to do things, for us to deal with it is very difficult, he has to be very patient (C1).

Sometimes she is aggressive with me, she treats me with harsh words, it doesn't matter if she complains about me, or suddenly wants me around her. This is exhausting (C3).

She spent an aggressive time (C4).

The instructional and assistance contribution that the caregivers receive from the health teams was ineffective so that they have the minimum condition to play a good role as care. The absence of any mention of information about the disease and the care provided by the nursing team to these caregivers, who found themselves in the situation of having to provide services for which they had no capacity or preparation, the absences of physiotherapy professionals and psychologists were also mentioned.

My biggest difficulty is, how to get her to treat... bathe for example, I don't know exactly where and how to get her, we don't have a nurse constantly (C8).

I had to get a person to help me bathe her. There were bedsores (pressure injuries) on her, and I am not a nursing technician, but I used to bandage her because there was no one else to do it (C3).

Physiotherapist and speech therapist comes once lost, so we have to turn to what we have, I needed to make dressing without knowing right but I did, exercise "phono" I saw the first time and
I keep trying, I make food and implant by the probe, I do all this. A psychologist would also help a lot, because you keep creating $N$ things in your mind and I keep thinking a lot: what am I going to do to help and save my mother?! (C10).

It's all very difficult with her, she turns, she goes astray, a person just can't do her cleaning (C9).

I think that a physiotherapist and a speech therapist would help, although it is a right, in practice we don't have it, the city hall gives support, material, but the professional doesn't show up, that's why it is difficult for us to take so much care of Mom, because it is limited, it would have more quality in care, but unfortunately we don't have the professionals who are legal, neither doctor, nor nursing staff, the care comes once or twice (C7).

It was possible to interpret in a general way that there is a certain disconnection of the caregivers with their own reality, many of them showed a certain indifference when talking about Alzheimer's, which shows the lack of information about the disease, leading them to be oblivious to the progress of the disorder. What demands maximum urgency is the change in the performance of health teams that need to be more active and offer these caregivers the full range of information, observe the overload of the caregiver's role, guide as to the procedures they will perform and seek alternatives for the welfare of the family caregiver, such as support groups, conversation wheels and psychological monitoring, these are alternatives to minimize the weight of the task they perform.

Faced with the diagnosis and future consequences for all those involved, a range of emotions and the need to adapt to the new reality are perceived. Caregivers need time to reorganize physically and emotionally; this time should be enough for them to accept and adapt to the new scenario designed by the disease in their lives ${ }^{8}$.

\section{CONCLUSION}

This study allowed us to know part of the routine of family caregivers of elderly people with 
Alzheimer's disease and allowed us to conclude that the task of caring is exhaustive and requires great responsibility. The process is painful and causes great changes in the daily life of the patient's family. It is worrying to realize how much living with an Alzheimer's disease patient changes the lifestyle and quality of life of those involved. It's a difficult time for patients and relatives. Watching your family member gradually lose their identity causes intense suffering and impotence, and the relationship with the patient becomes a confrontation with multiple and cumulative losses that need to be constantly adapted. The task of caring for a family member with $A D$ presupposes the psychic illness of the caregiver, making them also need emotional health support.

It is up to health professionals, especially nurses, to develop support practices for caregivers, such as support groups, which allow them to share experiences and express their feelings, promote greater acceptance of the illness and improve adaptability, stimulate selfcare, shared care and division of tasks, and allow social integration and exchange with peers. Thus, the caregiver will have a better quality of life and will be able to exercise a safer and less stressful home care.

\section{REFERENCES}

1. Santiago RS. Contemporary family law: constitutionalised family entity. Inter. Cient. 2013 fevereiro [access: 26 maio 2018]; v.1 (21): [5766]. Available from: https://periodicos.set.edu.br/index.php/direito/arti cle/viewFile/415/225

2. Brasil MS. Ageing and health of the elderly person. $1^{1}$ edição. BVS Ministério da Saúde. Editora MS; 2007. Available from: http://bvsms.saude.gov.br/bvs/publicacoes/abca d19.pdf

3. Colomé ICS, Marqui ABT, Jahn AC, Resta DG, Carli R, Winck MT et al. Caring for institutionalized elderly: characteristics and difficulties of caregivers. Rev. Elet. de Enferm. 2011 [access: 09 março 2019]; v. 13 (2): [306-312]. Available from:

https://www.fen.ufg.br/revista/v13/n2/v13n2a17.h $\mathrm{tm}$
4. Nascimento LC, Moraes ER, Silva JC, Veloso LC, Vale ARMC. Elderly caregiver: knowledge available in the LILACS database. Rev. Bras. de Enferm. 2008 [access: 09 março 2019]; v.61 (4): [514-517]. Available from: http://www.scielo.br/pdf/reben/v61n4/19.pdf

5. Ximenes MA, Rico BLD, Pedreira RQ.Alzheimer's disease: addiction and care. Rev. Kairós Geront., 2014 [access: 22 novembro 2018]; v. 17 (2): [121140]. Available from: https://revistas.pucsp.br/index.php/kairos/article/v iewFile/21630/15877

6. Galvão AM. Alzheimer's Dementia [Polytechnic Institute of Braganza]. IPB, Bragança: Esc Sup Saúde; 2011 [access: 21 maio 2018]. Available from:

https://bibliotecadigital.ipb.pt/bitstream/10198/12 792/1/Dem\%C3\%AAncia\%20de\%20Alzheimer.p df

7. Associação BA. Care of the family caregiver [Brazilian Alzheimer's Association]. São Paulo: ABRAZ; 2010 [access: 22 novembro 2018]. Available from: http://abraz.org.br/web/orientacao-acuidadores/cuidados-com-o-familiar-cuidador/oestresse-do-cuidador/

8. Valim MD, Damasceno DD, Abi-acl LC, Garcia F, Fava SMCL. Alzheimer's disease in the caregiver's vision: a case study. Rev. Elet. de Enferm., 2010 [access: 05 junho 2018]; v.12 (3): [528-534]. Available from: https://www.fen.ufg.br/revista/v12/n3/v12n3a16.h $\mathrm{tm}$

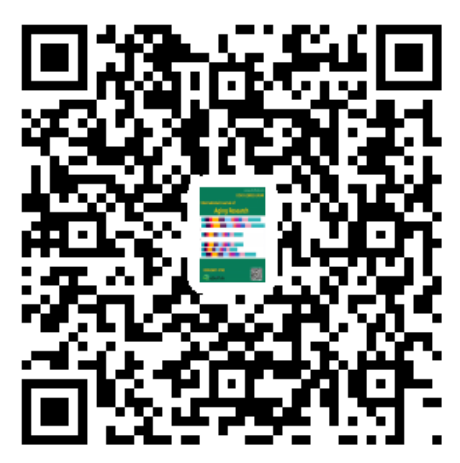

